\title{
Associação entre a Antropometria e a Leptina Circulante nos Compartimentos Materno, Fetal e Placentário, na Gravidez Normal
}

\author{
Association Between Anthropometry and Circulating Leptin in Maternal, \\ Fetal and Placental Compartments, in Healthy Pregnancy
}

Flávia Cipriano Castro, Henrique Vitor Leite, Alamanda Kfoury Pereira, Zilma Silveira Nogueira Reis, Antônio Carlos Vieira Cabral

\section{RESUM0}

Objetivo: avaliar a importância da leptina materna e fetal circulantes na gestação saudável por meio da avaliação de sua associação com variáveis antropométricas materna, placentária e fetal ao nascimento e as relações entre os compartimentos avaliados.

Métodos: em estudo transversal foi incluida amostra de 33 gestações únicas, a termo, com fetos saudáveis. As variáveis avaliadas foram idade materna, peso materno, índice de massa corporal, peso do recém-nascido, peso placentário e índice placentário. Amostras de sangue materno foram obtidas imediatamente antes do parto e em sangue do cordão umbilical ao nascimento. A dosagem da leptina sérica foi realizada por meio de radioimunoensaio convencional. As relações entre as concentrações de leptina sérica materna e da artéria e veia umbilicais com as variáveis de estudo foram verificadas através da regressão linear. Resultados: a leptina foi detectada no sangue de todas as 33 gestantes e seus respectivos recém-nascidos, sendo a concentração no sangue materno $(17,1 \pm 1,77 \mathrm{ng} / \mathrm{ml})$ superior à dos

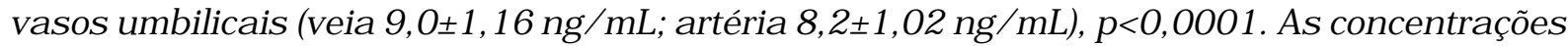
de leptina no sangue materno correlacionaram-se com as concentrações de leptina no sangue fetal (artéria: coef 0,63 p=0,037, veia: coef 0,72, p=0,006). Em relação aos dados antropométricos, a leptina medida no sangue materno mostrou associação com o índice de massa corporal materno inicial e final (coef 1,13; $p=0,002$ e coef 1,18, $p=0,001$ ) e os níveis de leptina no sangue de cordão apresentaram correlação com o peso fetal ao nascimento (veia: coef 0,007, $p=0,02$ e artéria: coef 0,006, $p=0,02$ ).

Conclusões: as produções materna e fetal de leptina correlacionaram-se entre si $e$ possivelmente respondem a estimulos semelhantes durante a gestação. A leptina sérica associou-se ao peso do compartimento onde circula.

PALAVRAS-CHAVE: Desenvolvimento fetal. Leptina. Sangue fetal. Peso fetal. Placenta. Gravidez normal.

\section{Introdução}

Estudos recentes têm revelado que a leptina tem ampla variedade de efeitos biológicos, com di-

Centro de Medicina Fetal do Hospital das Clínicas da Universidade Federal de Minas Gerais Correspondência:

Antônio Carlos Vieira Cabral

Centro de Medicina Fetal do Hospital das Clínicas da

Universidade Federal de Minas Gerais

Av. Alfredo Balena, 190, $4^{\circ}$ andar

30130-100 - Belo Horizonte - MG

Fone/FAX: (031) 3248-9421 / 9991-8256

e-mail: accabral@hc.ufmg.br versas funções neuroendócrinas e reprodutivas na espécie humana. Há evidências de que seu principal sítio de ação seja o hipotálamo, atuando na modulação do eixo hipotalâmico-hipofisáriogonadal $^{1}$. A leptina, produto do gene $o b$, é normalmente sintetizada e secretada pelo tecido adiposo $^{2,3}$, mas também pode ser produzida em outras locais como placenta, ossos, cartilagens, trato gastrointestinal e cérebro ${ }^{4,5}$.

Os níveis de leptina estão aumentados durante a gestação humana e a expressão placentária da leptina, assim como de seus receptores, foi recentemente descoberta ${ }^{6,7}$. Estes estu- 
dos mostraram que a leptina atua como um fator de crescimento fetal e no recém-nascido. Sabe-se também que a concentração de leptina fetal correlaciona-se com a idade gestacional, fato que é consistente com o padrão de desenvolvimento do tecido adiposo e acúmulo de massa adiposa pelo feto no transcorrer da gravide $z^{8}$.

A expressão da leptina placentária foi demonstrada pela detecção do RNA mensageiro da leptina em placentas desde a gestação inicial até gestações a termo ${ }^{8}$. Entretanto, a relação entre a leptina materna e do sangue do cordão e o crescimento fetal ainda não foi completamente elucidada ${ }^{9}$.

Neste estudo foram investigadas as concentrações de leptina no sangue materno e do cordão umbilical de gestações saudáveis, a relação entre elas, bem como a associação destes niveis com o peso materno, fetal e placentário.

\section{Pacientes e Métodos}

Trata-se de estudo transversal realizado em população de trinta e três mulheres com gestação a termo, submetidas à operação cesariana, na Maternidade do Hospital das Clínicas da Universidade Federal de Minas Gerais, entre março de 2001 e março de 2002. Todas as pacientes eram portadoras de gestações sem complicações. O termo de consentimento informado e aprovado previamente pelo Comitê de Ética da Instituição foi obtido de cada paciente, antes de sua inclusão no estudo (COEP 071/2001).

A idade gestacional no parto foi calculada de acordo com o último período menstrual e confirmada por ultra-sonografia antes da $20^{\mathrm{a}}$ semana de gestação. As indicações para a cesariana eletiva incluíram cesarianas prévias, apresentação pélvica e desproporção cefalopélvica, sendo excluídos os casos de cesarianas de emergência, tais como os envolvendo sofrimento fetal, assim como gestações pré e pós-termo. Também foram critérios de exclusão na seleção dos casos, as pacientes portadoras de diabete (prévio ou gestacional), doenças hipertensivas na gravidez (pré-eclâmpsia, hipertensão arterial crônica e hipertensão transitória), endocrinopatias, isoimunização pelo fator Rh ou que fizeram uso de corticóides.

Em relação aos fetos foram critérios de exclusão a suspeita de crescimento intra-uterino restrito ou macrossomia, independentemente da etiologia, e recém-nascidos com características dismórficas, malformações congênitas, infecções intra-uterinas, outros distúrbios orgânicos ou anomalias cromossômicas.
As variáveis demográficas avaliadas na gestante incluíram a idade materna em anos, o peso materno e o índice de massa corporal (IMC). O IMC foi calculado dividindo-se o peso em quilogramas pela altura em metros elevada ao quadrado, sendo que o peso utilizado no início da gestação era aquele informado no cartão de pré-natal da gestante e o final aferido à internação. As variáveis obstétricas incluíram o peso do recém-nascido e o peso placentário. Os recém-nascidos e as placentas foram pesadas dentro dos primeiros 60 minutos, após cesariana eletiva, sempre pelo mesmo examinador. Empregou-se a balança, no interior do bloco obstétrico. Os recém-nascidos foram classificados como de peso adequado para idade gestacional, utilizando-se a classificação proposta no serviço ${ }^{10}$.

Para a placenta, era previamente removido o cordão umbilical, as membranas e os coágulos retroplacentários e aguardava-se o escoamento do sangue dos vasos coriais e do espaço intervilositário por cinco minutos. $\mathrm{O}$ índice placentário foi calculado para cada caso dividindo-se o peso da placenta em gramas pelo peso do neonato também em gramas. Utilizaram-se valores até a quarta casa decimal ${ }^{11}$.

A dosagem da leptina foi realizada a partir de amostras de sangue materno obtidas imediatamente antes do parto, em veia periférica, e do cordão umbilical, ao nascimento. Durante a realização da cesariana, logo após a histerotomia e extração fetal, foi feita a ligadura do cordão umbilical, sendo retirado deste um segmento e realizada a coleta de $2 \mathrm{~mL}$ de sangue venoso e arterial em frasco sem anticoagulante. As alíquotas de soro foram obtidas por centrifugação e as amostras prontamente armazenadas, em duplicata, a $-80^{\circ} \mathrm{C}$, em tambor de nitrogênio líquido, até a data de realização da dosagem.

A dosagem das concentrações de leptina foi realizada por meio de radioimunoensaio convencional (RIA), utilizando-se o Human Leptin RIA kitcatálogo HL-81K, fabricado por Linco Research, Inc. O volume da amostra biológica foi de 100 microlitros. A sensibilidade foi de $0,5 \mathrm{ng} / \mathrm{mL}$. Os coeficientes médios de variação inter e intra-ensaio foram 4,5 e 4,9\%, respectivamente.

Para análise estatística, as relações entre as concentrações de leptina sérica materna, da artéria e veia umbilicais com o peso do recémnascido, o peso placentário, o índice placentário e IMC materno foram avaliadas utilizando-se regressão linear (Programa Minitab Inc. ${ }^{\circledR}$, version 11.12 , 1996). Os resultados da análise de regressão foram apresentados pelo coeficiente de regressão, poder de explicação da equação $\left(\mathrm{R}^{2}\right)$ e significância estatística do modelo de regressão (p). O Coef (coeficiente de regressão) mede a força de correlação entre as variáveis, sendo maior tanto 
maior seu valor e considerado significativo quando $\mathrm{p}<0,05$. Todos os resultados foram considerados válidos em nível de significância de $5 \%(\mathrm{p}<0,05)$, tendo, portanto, $95 \%$ de confiabilidade de que estejam corretos.

\section{Resultados}

Os dados clínicos das mães e dos neonatos foram rezumidos na Tabela 1 . Todos os recémnascidos do estudo foram considerados adequados para a idade gestacional, segundo a classificação empregada.

Tabela 1 - Caracterização do grupo de estudo e valores relacionados aos recémnascidos e placenta.

\begin{tabular}{lcc} 
& $\begin{array}{c}\text { Média } \pm \text { desvio } \\
\text { padrão }\end{array}$ & Amplitude \\
\hline Idade materna (anos) & $29 \pm 7$ & $15-39$ \\
Idade gestacional (semanas) & $39 \pm 1$ & $37-42$ \\
Peso materno inicial $(\mathrm{kg})$ & $63,4 \pm 11,5$ & $44,0-91,0$ \\
Peso materno final $(\mathrm{kg})$ & $74,7 \pm 10,8$ & $50-94,9$ \\
IMC materno inicial $\left(\mathrm{kg} / \mathrm{m}^{2}\right)$ & $20 \pm 5$ & $17-35$ \\
IMC materno final $\left(\mathrm{kg} / \mathrm{m}^{2}\right)$ & $30 \pm 5$ & $20-38$ \\
Peso fetal ao nascimento $(\mathrm{g})$ & $3.156 \pm 364$ & $2.535-3.775$ \\
Peso placentário $(\mathrm{g})$ & $463 \pm 87$ & $295-745$ \\
Índice placentário & $0,147 \pm 0,025$ & $0,116-0,227$
\end{tabular}

Tabela 2 - Concentrações de leptina sérica materna e no sangue de cordão (Médias e erro padrão).

\begin{tabular}{lr}
\hline Compartimento & Média \pm EP \\
\hline $\begin{array}{l}\text { Sangue materno }(\mathrm{ng} / \mathrm{mL}) \\
\text { Sangue fetal }\end{array}$ & $17,1 \pm 1,77^{\star}$ \\
$\quad$ Veia umbilical $(\mathrm{ng} / \mathrm{mL})$ & $9,0 \pm 1,16$ \\
$\quad$ Artéria umbilical $(\mathrm{ng} / \mathrm{mL})$ & $8,2 \pm 1,02$ \\
\hline $\begin{array}{l}\text { Obs: } \\
\text { (p<0alor significativamente superior ao sangue da veia e da artéria umbilical }\end{array}$
\end{tabular}

A leptina foi detectada no sangue de todas as 33 gestantes e seus respectivos recém-nascidos, sendo a concentração no sangue materno $(17,1 \pm 1,77 \mathrm{ng} / \mathrm{mL})$ superior à dos vasos umbilicais (veia: 9,0 $\pm 1,16 \mathrm{ng} / \mathrm{mL}$; artéria: $8,2 \pm 1,02 \mathrm{ng} / \mathrm{mL}$ ), como apresentado na Tabela 2.

As concentrações de leptina no sangue materno correlacionaram-se com as concentrações de leptina no sangue fetal, obtidas na artéria (coeficiente de regressão $0,63, p=0,037$ ) e veia umbelicais (coeficiente de regressão 0,72, $\mathrm{p}=0,006$ ) (Tabela 3). Nos vasos umbilicais, a concentração venosa de leptina encontrada $(9,0 \pm 1,16 \mathrm{ng} / \mathrm{mL})$ foi ligeiramente superior à concentração na artéria umbilical $(8,2 \pm 1,02 \mathrm{ng} / \mathrm{mL})$. Em análise pareada ( $t$ de Student pareado), essa diferença foi significativa $(p=0,029)$. A correlação entre as concentrações de leptina dos dois vasos umbilicais também foi significativa e positiva $($ coef $=0,96 ; \mathrm{p}<0,0001)$.

Em relação aos dados antropométricos, os níveis de leptina no sangue materno mostraram associação com o IMC materno inicial e final (coeficiente de regressão $1,13, \mathrm{p}=0,002$ e coeficiente de regressão $1,18, \mathrm{p}=0,001$, respectivamente), mas não com o peso do recém-nascido, placenta ou índice placentário. Por outro lado, os níveis de leptina no sangue do cordão associaram-se ao peso ao nascimento, sendo em sangue venoso: coeficiente de regressão 0,007, p=0,02, e em sangue arterial: coeficiente de regressão $0,006, p=0,02$, sem contudo se correlacionar ao IMC materno inicial, final ou peso placentário e o índice placentário (Tabela 3).

\section{Discussão}

O estudo do papel da leptina nos compartimentos materno e fetal durante a gestação é desafiador e abre importantes perspectivas no en-

Tabela 3 - Correlação entre as concentrações de leptina em sangue materno e fetal e as variáveis de estudo.

\begin{tabular}{lcccccc}
\hline & \multicolumn{2}{c}{ Leptina no sangue materno } & \multicolumn{3}{c}{ Leptina no cordão umbilical } \\
& \multicolumn{2}{c}{} & \multicolumn{2}{c}{ Sangue venoso } & \multicolumn{2}{c}{ Sangue arterial } \\
& & $\mathbf{R}^{2}(\%)$ & Coef & $\mathbf{R}^{2}(\%)$ & Coef & $\mathbf{R}^{2}(\%)$ \\
\hline Leptina no sangue materno & $\ldots$ & $\ldots$ & 0,72 & $22,1^{*}$ & 0,63 & $13,4^{*}$ \\
Leptina no sangue de cordão (venoso) & $\ldots$ & $\ldots$ & $\ldots$ & $\ldots$ & 0,85 & $92,4^{*}$ \\
IMC materno inicial & 1,13 & $26^{*}$ & 0,34 & 5,5 & 0,33 & 6,5 \\
IMC materno final & 1,18 & $28,9^{*}$ & 0,31 & 4,6 & 0,24 & 3,5 \\
Peso ao nascimento & 0,007 & 7 & 0,007 & $16,4^{*}$ & 0,006 & $15,5^{*}$ \\
Peso da placenta & 0,02 & 4,1 & 0,07 & 0,8 & 0,002 & 0,1 \\
Índice placentário & 17,3 & 0,2 & 53,8 & 4 & 59,6 & 6,3 \\
\hline
\end{tabular}

Nota: (*) significante: $p<0,05$; Coef: coeficiente de regressão, $R^{2}$ : poder de explicação do modelo. 
tendimento do crescimento fetal. Sabe-se que esta regulação é complexa e multifatorial, estando em muitos casos relacionada a mau prognóstico da gestação $^{12}$. Seus mecanismos controladores ainda estão sendo elucidados, mas sem dúvida existe interação entre fatores nutricionais, taxa de maturação e proliferação celular durante a vida intra-uterina, além de condições intrínsecas maternas, fetais e placentárias ${ }^{13,14}$.

Neste estudo, a detecção de leptina no sangue do cordão umbilical arterial e venoso em todas as gestantes e recém-nascidos confirma a síntese e secreção fetal de leptina já descrita ${ }^{15,16}$.

No que se refere ao compartimento materno, a verificação de correlação entre a leptina circulante materna e o IMC poderia refletir a expansão da massa de tecido gorduroso durante a gestação, uma vez que alterações na massa corporal, a produção placentária e o estímulo por parte de outros hormônios gestacionais são fatores que poderiam levar ao aumento nos níveis de leptina no período gestacional ${ }^{17}$. Além disto, o fato de os niveis de leptina na gestante serem mais elevados do que na paciente não grávida e reduzirem abruptamente para níveis pré-gestacionais no período pós-parto sugere que uma quantidade de leptina no sangue materno durante a gestação se origina da placenta ${ }^{18}$.

Não foram encontradas, neste estudo, correlações entre os niveis de leptina materna com o peso placentário, como em outros ${ }^{4}$, e entre aquela variável e o índice placentário. Em geral, a secreção placentária de hormônios (i.e,. estrogênios, progesterona, prolactina e hormônio lactogênio placentário) é relacionada ao aumento do peso placentário ${ }^{19}$. É possível que a secreção de leptina pela placenta atinja um platô durante o segundo trimestre de gestação e que não acompanhe o crescimento placentário ${ }^{12}$. De fato, a expressão do RNA mensageiro da leptina parece declinar durante a gestação, em contraste com o aumento dos níveis de leptina no plasma materno ${ }^{8}$.

No compartimento fetal, devido ao seu alto peso molecular a leptina materna não atravessa a barreira placentária e sua presença no sangue do cordão sugere que ela seja produzida intra-útero. Desta forma, a correlação encontrada entre a leptina materna e a do sangue do cordão observada neste estudo e em outros ${ }^{20}$ leva a crer que ela possa indiretamente influenciar os níveis circulantes fetais. Uma possível explicação para o fato seria um fator fetal geneticamente determinado regulando sua produção e não simplesmente a associação à massa de tecido adiposo fetal. Trabalhos anteriores têm mostrado que os níveis plasmáticos de leptina nos vasos do cordão umbilical se correlacionam com o peso neonatal ${ }^{12,15,21}$, podendo refletir, no feto, um sinal para a expan- são de suas reservas de gordura corporal. Nesta casuística, a correlação encontrada entre os níveis de leptina no cordão umbilical tanto arterial quanto venoso com o peso dos recém-nascidos sugeriria, portanto, um papel para a leptina como regulador do peso e crescimento fetal.

Também na presente investigação os níveis de leptina na veia umbilical foram significativamente mais elevados do que os níveis na artéria umbilical, assim como em outros ${ }^{15,16,22}$, e houve uma correlação importante entre os níveis de leptina nos sangues venoso e arterial do cordão. Esses dados são consistentes com a hipótese de que ocorre secreção de leptina da placenta para a circulação fetal e que, possivelmente, a produção de leptina pela placenta seja maior do que a sintese pelo tecido fetal, em neonatos adequados para a idade gestacional. No entanto, o mecanismo de liberação aumentada de leptina pela placenta durante a gestação e ao termo parece ser multifatorial. A leptina parece exercer importante papel na adaptação fetal ao estresse gasto energético. Tem sido sugerido que a leptina derivada da placenta e presente na veia umbilical é responsável pela regulação do metabolismo e desenvolvimento fetal ${ }^{12}$.

Por outro lado, foi demonstrado recentemente que da produção total de leptina pela placenta, 98,4\% é liberada na circulação materna e 1,6\% na circulação fetal ${ }^{17}$. Contudo, a importância da leptina placentária para o feto continua incerta. Considerando-se a população estudada, não foi encontrada uma correlação significativa entre as concentrações de leptina materna e do sangue do cordão umbilical arterial e venoso com o peso e o indice placentários, sugerindo que a produção de leptina e liberação pela placenta no compartimento fetal não sejam função da massa placentária, mas podem ser moduladas por um ou mais fatores de origem extraplacentária.

As contribuições deste estudo, pioneiro em nosso meio, foram as constatações das relações entre este hormônio nos compartimentos materno, fetal e placentário, acrescentando evidências para o entendimento do papel deste hormônio na gestação normal.

\section{ABSTRACT}

Purpose: to evaluate the importance of circulating maternal and fetal leptin in the healthy gestation, using its association with maternal, placental and fetal anthropometric variables, obtained at birth, and the relationship between the evaluated compartments.

Methods: in a transversal study a population of 33 single, healthy and term gestations was studied. The evaluated variables were maternal age, maternal weight, body mass 
index (BMF), weight of the newborn, placental weight, and placental index. Samples of maternal blood were immediately obtained before birth and from fetal umbilical cord blood at birth. Determination of serum leptin was performed using conventional radioimmunoassay. The relationships between serum leptin concentrations in maternal blood, umbilical artery and vein and the studied variables were assessed through linear regression.

Results: leptin levels were detected in the blood of all 33 pregnant women and their respective newborns, with maternal blood concentration $(17.1 \pm 1.77 \mathrm{ng} / \mathrm{mL})$ higher than that of umbilical vessels (vein: $9.0 \pm 1.16 \mathrm{ng} / \mathrm{mL}$; artery: $8.23 \pm 1.02$ $n g / m L), p<0.0001$. Leptin concentrations in the maternal blood were correlated with leptin concentrations in fetal blood (artery: coef. 0.63, $p=0.037$; vein: coef. 0.72, $p=0.006$ ). Regarding the anthropometric variables, leptin measured in the maternal blood was associated with initial and final maternal BMF (coef. 1.13; $p=0.002$; coef. 1,18, $p=0.001$ ) and cord leptin levels were correlated with the fetal weight at birth (vein: coef. 0.007, $p=0.02$; artery: coef. 0.006, $p=0.02$ ).

Conclusions: there was a correlation between maternal and fetal leptin production and probably by the action of similar stimuli during gestation. Serum leptin was associated with the weight of the compartment where it circulates.

KEYWORDS: Fetal development. Leptin. Fetal blood. Fetal weight. Placentae. Normal pregnancy.

\section{Referências}

1. Schwartz MW, Baskin DG, Bukowski TR, et al. Specificity of leptin action on elevated blood glucose levels and hypothalamic neuropeptide Y gene expression in ob/ob mice. Diabetes 1996; 45:531-5.

2. Zhang Y, Proenca R, Maffei M, Barone M, Leopold L, Friedman JM. Positional cloning of the mouse obese gene and its human homologue. Nature 1994; 372:425-32.

3. Considine RV, Sinha MK, Heiman ML, et al. Serum immunoreactive-leptin concentrations in normal weight and obese humans. N Engl J Med 1996; 334:292-5.

4. Butte NF, Hopkinson JM, Nicolson MA. Leptin in human reproduction: serum leptin levels in pregnant and lactating women. J Clin Endocrinol Metab 1997; 82:585-9.

5. Wiesner G, Vaz M, Collier, G, et al. Leptin is released from the human brain: inluence of adiposity and gender. J Clin Endocrinol Metab 1999; 84:2270-4.

6. Masuzaki H, Ogawa Y, Sagawa N, et al. Nonadipose tissue production of leptin: leptin as a novel placenta-derived hormone in humans. Nat Med 1997; 3:1029-33.

7. Hassink SG, de Lancey E, Sheslow DV, et al. Placental leptin: an important new growth factor in intrauterine and neonatal development? Pediatrics 1997; 100:E1.

8. Henson MC, Swan KF, O'Neil JS. Expression of placental leptin and leptin receptor transcripts in early pregnancy and at term. Obstet Gynecol 1998; 92:1020-8.

9. Cetin I, Morpurgo PS, Radaelli T, et al. Fetal plasma leptin concentrations: relationship with different intrauterine growth patterns from 19 weeks to term. Pediatr Res 2000; 48:646-51.

10.Lubchenco LO, Hansman C, Dressler M, Boyd E. Intrauterine growth as estimated from liveborn birth-weight data at 24 to 42 weeks of gestation. Pediatrics 1963; 32:793-800.

11. Matheus M, Sala MA. Curvas do índice placentário durante a segunda metade da gestação. Rev Bras Ginecol Obstet 1985; 7:142-5.

12.Sivan E, Lin WM, Homko CJ, Reece EA, Boden G. Leptin is present in human cord blood. Diabetes 1997; 46:917-9.

13. Christou H, Connors JM, Ziotopoulou M, et al. Cord blood leptin and insulin-like growth factor levels are independent predictors of fetal growth. J Clin Endocrinol Metab 2001; 86:935-8.

14.Koistinen HA, Koivisto VA, Andersson S, et al. Leptin concentration in cord blood correlates with intrauterine growth. J Clin Endocrinol Metab 1997; 82:3328-30.

15.Mounzih K, Qiu J, Ewart-Toland A, Chehab FF. Leptin is not necessary for gestation and parturition but regulates maternal nutrition via a leptin resistance state. Endocrinology 1998; 139:5259-62.

16.Schubring C, Kiess W, Englaro P, et al. Levels of leptin in maternal serum, amniotic fluid, and arterial and venous cord blood: relation to neonatal and placental weight. J Clin Endocrinol Metab 1997; 82:1480-3.

17.Yura S, Sagawa N, Mise H, et al. A positive umbilical venous-arterial difference of leptin level and its rapid decline after birth. Am J Obstet Gynecol 1998; 178:926-30.

18.Linnemann K, Malek A, Schneider H, Fusch C. Physiological and pathological regulation of feto/ placento/maternal leptin expression. Biochem Soc Trans 2001; 29:86-90.

19.Geary M, Pringle PJ, Persaud M, et al. Leptin concentrations in maternal serum and cord blood: relationship to maternal anthropometry and fetal growth. Br J Obstet Gynaecol 1999; 106:1054-60.

20.Aspillaga MO, Whittaker PG, Taylor A, Lind T. Some new aspects of the endocrinological response to pregnancy. Br J Obstet Gynaecol 1983; 90:596-603.

21.Varvarigou A, Mantzoros CS, Beratis NG. Cord blood leptin concentrations in relation to intrauterine growth. Clin Endocrinol (Oxf) 1999; 50:177-83.

22.Matsuda J, Yokota I, Iida M, et al. Serum leptin concentration in cord blood: relationship to birth weight and gender. J Clin Endocrinol Metab 1997; 82:1642-4. 